\title{
Initial Training: Teknik Pemeliharaan Kendaraan sebagai Sarana Pemenuhan Kompetensi Personel PKP-PK dalam Kesiapsiagaan Kendaraan Operasional
}

\author{
Anton Abdullah ${ }^{1}$, Wildan Nugraha ${ }^{2}$, Sutiyo $^{3}$, Reyvaldo Fajriansyah Setiawan ${ }^{4}$, \\ Muhammad Iqbal Dwi Saputra ${ }^{5}$, Ridho Priyama Putra ${ }^{6}$ \\ Program Studi Diploma III Penyelamatan dan Pemadam Kebakaran Penerbangan \\ Politeknik Penerbangan Palembang \\ e-mail: anton@poltekbangplg.ac.id
}

\begin{abstract}
Abstrak
Tujuan kegiatan ini adalah peserta pelatihan mampu melakukan pemeliharaan kendaraan Pertolongan Kecelakaan Penerbangan dan Pemadam Kebakaran (PKP-PK) dengan baik dan benar sesuai dengan peraturan yang berlaku dan buku manual kendaraan PKP-PK. Metode yang digunakan adalah competency-based training, proses belajar di kelas untuk teori dan menggunakan trainer dan simulator untuk kegiatan praktik untuk pemenuhan knowledge, skill and attitude untuk personel PKP-PK bandar udara. Kegiatan initial training Teknik Pemeliharaan Kendaraan PKP-PK secara keseluruhan berjalan dengan baik dan lancar, dengan ratarata nilai evaluasi 80,614 (kualifikasi: baik) sebagai indikator bahwa tujuan pembelajaran telah tercapai.
\end{abstract}

Kata Kunci: competency-based training, initial training, personel PKP-PK

\begin{abstract}
The purpose of the activity is that the trainees are capable to conduct airport rescue and fire fighter (ARFF) vehicle maintenance properly based on any related regulations and manuals The methods used are competency-based training, classroom session for theoretical learning process, and practical session with trainers and simulators for the fulfillment of ARFF personnel knowledge, skills, and attitudes. ARFF Vehicle Maintenance Technique Initial Training went well and smoothly, with an average evaluation score of 80,614 (qualification: good), indicated that the learning objectives have been achieved.
\end{abstract}

Keywords: community service, competency base training, initial training, ARFF personnel

\section{Pendahuluan}

Sistem transportasi udara meliputi wahana transportasi, sarana dan prasarana transportasi, aturan regulasi, organisasi dan sebagainya. Ruang lingkup sistem transportasi udara yang luas membutuhkan tantangan tersendiri dalam perawatan yang memenuhi standar baku (Sefrus et al., 2017; Shulfi \& Sofyan, 2017). Dengan semakin kompleksnya sistem transportasi udara dan semakin berkembangnya pertumbuhan penggunaan jasa transportasi udara, maka semakin besar pula peluang akan terjadinya suatu kecelakaan. Walaupun kecelakaan ini sesuatu yang selalu berusaha dihindari, tetapi tetap kewaspadaan dan kesiapan akan terjadinya kecelakaan ini harus selalu ada. Oleh karena itu, salah satu standar yang harus dipenuhi oleh sebuah bandar udara adalah terdapatnya peralatan pertolongan kecelakaan penerbangan dan pemadam kebakaran atau yang dikenal dengan istilah peralatan PKP-PK. Peralatan ini sudah menjadi standar yang harus dipenuhi oleh setiap bandara di Indonesia sesuai dengan aturan regulasi yang berlaku. Peralatan PKP-PK ini harus selalu dalam kondisi yang baik dan siap pakai. Hal ini dengan pertimbangan, dalam pengoperasian transportasi udara setiap saat terdapat kemungkinan terjadinya suatu kecelakaan yang memerlukan tindakan segera dengan menggunakan peralatan PKP-PK ini (Kurikulum dan Silabus Perawatan Peralatan PKP PK, 2011).

Setiap penyelenggara bandar udara wajib melakukan pemeliharaan kendaraan dan peralatan penunjang operasi Pertolongan Kecelakaan Penerbangan dan Pemadam Kebakaran (PKP-PK) agar 
kinerja operasi dapat maksimum sesuai dengan kategori bandar udara untuk PKP-PK (MoS CASR 139 Vol. IV, 2015). Dengan pertimbangan itu, maka peralatan PKP-PK harus selalu dalam kondisi baik dan siap pakai setiap saat, karena kecelakaan biasa terjadi tanpa terjadwal dan tanpa adanya peringatan apa-apa. Agar peralatan tersebut dapat berfungsi dengan baik ketika dibutuhkan, maka peralatan ini harus selalu dijaga dan dipelihara secara rutin. Pemeliharaan peralatan tersebut, tidak dapat dilakukan secara asal-asalan, tapi harus dilakukan sesuai dengan aturan yang ada serta dilakukan oleh orang-orang yang telah dididik dan dilatih untuk melakukan pemeliharaan peralatan PKP-PK ini. Untuk itu perlu adanya suatu pendidikan dan pelatihan (diklat) pemeliharaan peralatan PKP-PK.

Berlatar belakang hal tersebut di atas, Prodi Diploma Tiga Penyelamatan da Pemadam Kebakaran Penerbangan (PPKP) Politeknik Penerbangan Palembang dengan keahlian di bidang Penyelamatan dan Pemadam Kebakaran Penerbangan berkomitmen penuh mendukung kegiatan Pengabdian kepada Masyarakat sebagai salah satu wujud dari Tridharma Pendidikan Tinggi. Dengan penyelenggaraan Initial Training: Teknik Pemeliharaan Kendaraan PKP-PK, diharapkan dapat memberikan pemahaman dan keahlian dasar yang tepat kepada masyarakat sebagai sarana pemenuhan Kompetensi Personel PKP-PK Bandar Udara dalam Kesiapsiagaan Kendaraan Operasional PKP-PK sesuai dengan Peraturan Direktur Jenderal Perhubungan Udara Nomor: KP.002 Tahun 2012 tentang Petunjuk dan Tata Cara Peraturan Keselamatan Penerbangan Sipil Bagian 13912, Lisensi dan Standar Kompetensi Personel Pertolongan Kecelakaan Penerbangan dan Pemadam Kebakaran.

Nugraha et al., (2021) kegiatan initial training telah memberikan pengalaman bagi peserta pelatihan melalui memberikan feedback yang positif terhadap pelayanan yang diberikan selama pelaksanaan pelatihan, hal tersebut dapat dilihat dari hasil evaluasi kegiatan yang secara menyeluruh berada di penilaian baik. Keterampilan yang memelihara kendaraan PKP-PK menentukan keamanan dalam dunia penerbangan sehingga dibutuhkan pelatihan agar kompeten dalam pemeliharaan (Lukina, 2015). Tingkat keberhasilan pelatihan perawatan mesin sangat ditentukan dari kesungguhan dan pengetahuan awal yang dimiliki peserta, kedua aspek dalam proses pelatihan perawatan memberikan bekal bagi peserta untuk meningkatkan keterampilan perawatan (Dudung et al., 2015 \& Arif et al., 2020).

Adapun tujuan kegiatan ini adalah setelah mengikuti pelatihan ini, para peserta pelatihan mampu melakukan pemeliharaan kendaraan PKP-PK dengan baik dan benar sesuai dengan peraturan yang berlaku dan buku manual kendaraan PKP-PK.

\section{Metode}

Metode yang digunakan untuk Pelatihan Teknik Pemeliharaan Kendaraan PKP-PK adalah dengan metode klasikal di Kampus Politeknik Penerbangan Palembang dengan mengacu pada metode training yang digunakan oleh International Civil Aviation Organization (ICAO) yaitu competencybased training, proses belajar di kelas untuk teori dan menggunakan trainer dan simulator untuk kegiatan praktik untuk pemenuhan knowledge, skill and attitude untuk personel PKP-PK bandar udara. Hal ini dilakukan demi mengakomodir kegiatan-kegiatan praktik yang harus menggunakan peralatan-peralatan praktik di Kampus Politeknik Penerbangan Palembang.

Protokol kesehatan tetap diterapkan dengan mewajibkan penggunaan masker pada tiap sesi kegiatan pembelajaran, sesi kegiatan harian di asrama dan pembatasan akses untuk keluar area kampus. Pengecekan genose dilakukan saat peserta tiba sebagai screening awal kegiatan. Swab test dilakukan pada saat peserta akan keluar kampus (setelah penutupan).

Lebih banyaknya jam praktek ( 92 jam pelajaran) daripada jam teori (58 jam pelajaran) dan latar belakang peserta yang memiliki pengalaman dalam otomotif sebelumnya, membuat Politeknik Penerbangan Palembang untuk lebih memilih metode pengajaran dengan menggunakan diskusi dan problem solving. Cara kerja mesin akan dijelaskan oleh dosen dengan menggunakan trainer-trainer 
mesin yang tersedia di laboratorium PKP-PK dan menerapkannya dalam sistem yang terdapat di kendaraan PKP-PK sesuai dengan kurikulum pelatihan yang berlaku (Tabel 1).

Tabel 1. Kurikulum Pelatihan Teknik Pemeliharaan Kendaraan PKP-PK

\begin{tabular}{llcc}
\hline \multirow{2}{*}{ No } & Mata Pelajaran & \multicolumn{2}{c}{ *Jumlah JP } \\
\cline { 2 - 3 } & Teori & Praktik \\
\hline 1 & Penjabaran Program Pelatihan & 2 & 0 \\
\hline 2 & Pengantar Pemeliharaan Kendaraan PKP-PK & 0 \\
\hline 3 & Pemeliharaan Mesin Kendaraan & 24 \\
\hline 4 & Pemeliharaan Kelistrikan Kendaraan & 8 \\
\hline 5 & Pemeliharaan Transmisi Kendaraan & 8 \\
\hline 6 & Pemeliharaan Rem, ban, dan Velg Kendaraan & 8 \\
\hline 7 & Pemeliharaan Sistem Pneumatik dan Hidrolik Kendaraan & 8 \\
\hline 8 & Pemeliharaan Sistem Pengendalian/ Kemudi & 4 \\
\hline 9 & Sistem Pemadam Kebakaran (Fire Fighting System) Kendaraan PKP-PK & 8 \\
\hline 10 & Pemeliharaan Peralatan Operasional dan Bahan Pendukungnya & 4 \\
\hline 11 & Sistem Dokumentasi, Sistem Pelaporan dan Program Pemeliharaan & 4 & 8 \\
\hline 12 & Ujian Komprehensif & 4 & $\mathbf{9 2}$ \\
\hline & Jumlah & 4 & $\mathbf{5 8}$ \\
\hline & Total Jam Pelajaran (JP) & $\mathbf{1 5 0}$ \\
\hline
\end{tabular}

Untuk mengakomodir keseluruhan total jam pelajaran yang harus dilaksanakan, 150 jam pelajaran, Pelatihan Teknik Pemeliharaan Kendaraan PKP-PK dilaksanakan selama 22 (dua puluh dua) hari, pada tanggal 7 Juni 2021 sampai dengan tanggal 28 Juni 2021, bertempat di Kampus Politeknik Penerbangan Palembang. Penilaian hasil belajar Pelatihan Teknik Pemeliharaan Kendaraan PKP-PK didasarkan atas penilaian kedisiplinan kehadiran peserta (bobot 25\%) dan hasil ujian komprehensif (bobot 75\%). Biaya penyelenggaraan Pelatihan Teknik Pemeliharaan Kendaraan PKP-PK bersumber dari peserta yang menjadi pemasukan Badan Layanan Umum (BLU) Politeknik Penerbangan Palembang.

\section{Hasil dan Pembahasan}

Kegiatan ini dilaksanakan berdasarkan Surat Keputusan Direktur Politeknik Penerbangan Palembang Nomor: SK.077/Poltekbang.Plg-2021 tanggal 7 Juni 2021, tentang Penyelenggaraan Pendidikan dan Pelatihan Teknik Pemeliharaan Kendaraan PKP-PK Angkatan I Tahun Anggaran 2021. Peserta pelatihan, berjumlah 8 (delapan) orang, telah memiliki pengalaman bekerja sebagai petugas PKP-PK bandar udara.

Proses belajar baik teori maupun praktik berjalan dengan lancar, dengan menggunakan protokol kesehatan yang ketat, jumlah peserta yang kurang dari jumlah peserta maksimal (20 orang) sangat membantu dalam pengaturan jarak di ruang kelas dan laboratorium. Seluruh mata pelajaran sesuai dengan kurikulum dan silabus telah dilaksanakan sesuai dengan jadwal dan diajarkan oleh dosen Program Studi PPKP Politeknik Penerbangan Palembang yang kompetensi dan keilmuannya sesuai dengan mata pelajaran yang diajarkan (dokumentasi kegiatan lihat Gambar 1). 
Hasil capaian pelatihan adalah keseluruhan peserta dinyatakan lulus dan berhak mendapatkan sertifikat kompetensi, dengan rincian hasil prestasi peserta seperti Tabel 2.

Tabel 2. Nilai Hasil Pelatihan

\begin{tabular}{cllc}
\hline No & Nama Peserta & Asal Instansi & Nilai \\
\hline 1 & Budi Priyanto & BP Batam & 80.02 \\
\hline 2 & Imam Hari Sumbodo & BP Batam & 86.54 \\
\hline 3 & Jansen Nababan & BP Batam & 77.15 \\
\hline 4 & Jefri Debos Hasadaon Sinaga & BP Batam & 82.09 \\
\hline 5 & Rayusman & BP Batam & 81.04 \\
\hline 6 & Setiyono & BP Batam & 81.18 \\
\hline 7 & Fadil Satrio Pebrianto & Indopelita Air Service & 79.15 \\
\hline 8 & Sigit Suyanto & UPBU H. Hasan Aroeboesman, Ende & 77.15 \\
\hline
\end{tabular}

Guna meningkatkan layanan pelatihan yang diberikan oleh Politeknik Penerbangan Palembang, maka disebarkan kuisioner terkait evaluasi kegiatan kepada seluruh peserta pelatihan dengan rincian hasil seperti Grafik 1. Hasil evaluasi terkait penilaian penyelenggaraan pelatihan, dari 8 peserta yang mengisi evaluasi, 42\% menyatakan Sangat Setuju bahwa penyelenggaraan pelatihan telah dilaksanakan secara positif, 36\% menyatakan Setuju, 14\% menyatakan netral, $8 \%$ menyatakan tidak setuju, dan tidak terdapat penyataan Sangat Tidak Setuju.

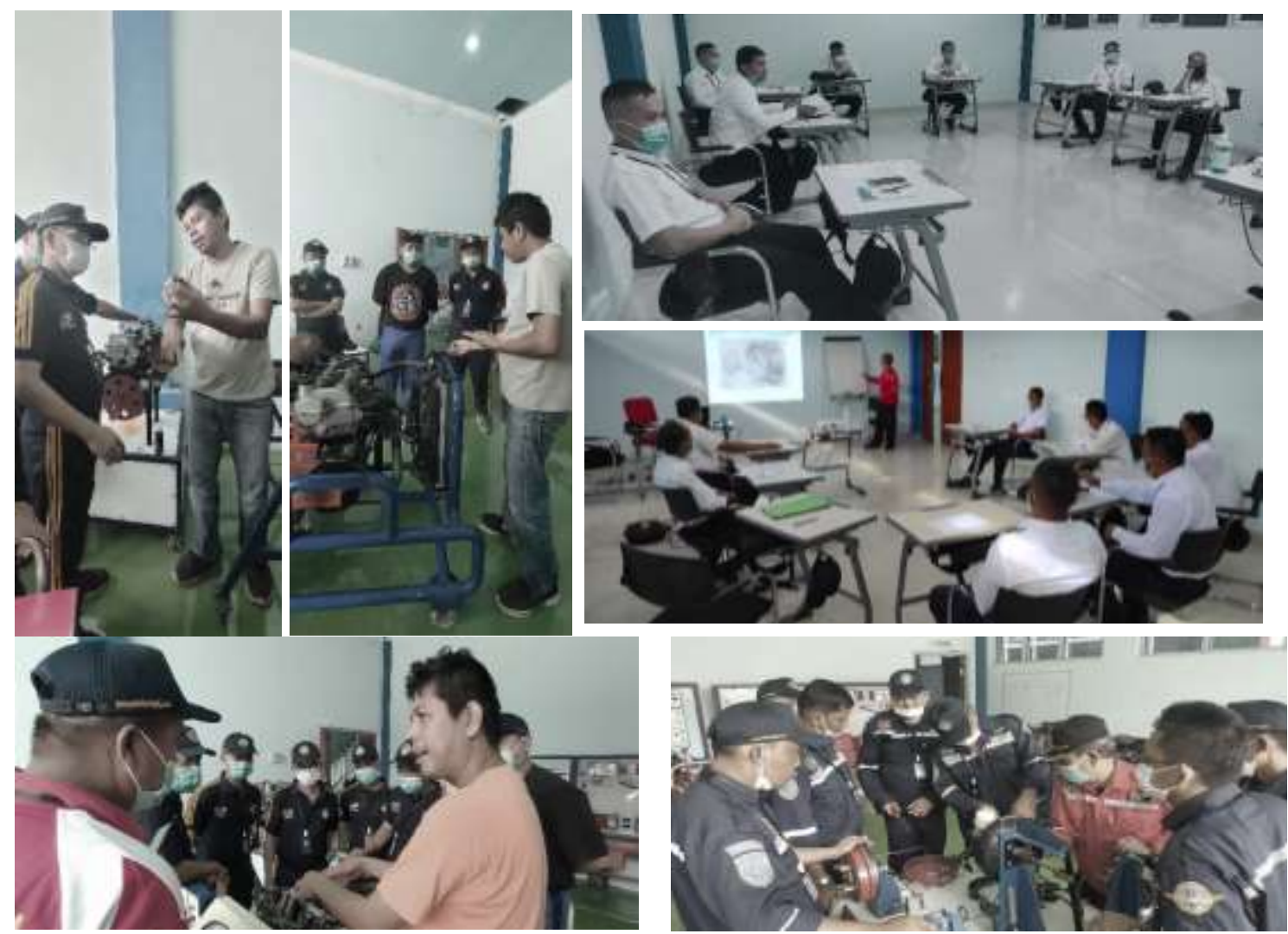

Gambar 1. Dokumentasi Pelaksanaan

Darmabakti: Jurnal Inovasi Pengabdian dalam Penerbangan

Volume 2, Nomor 1, Desember 2021 


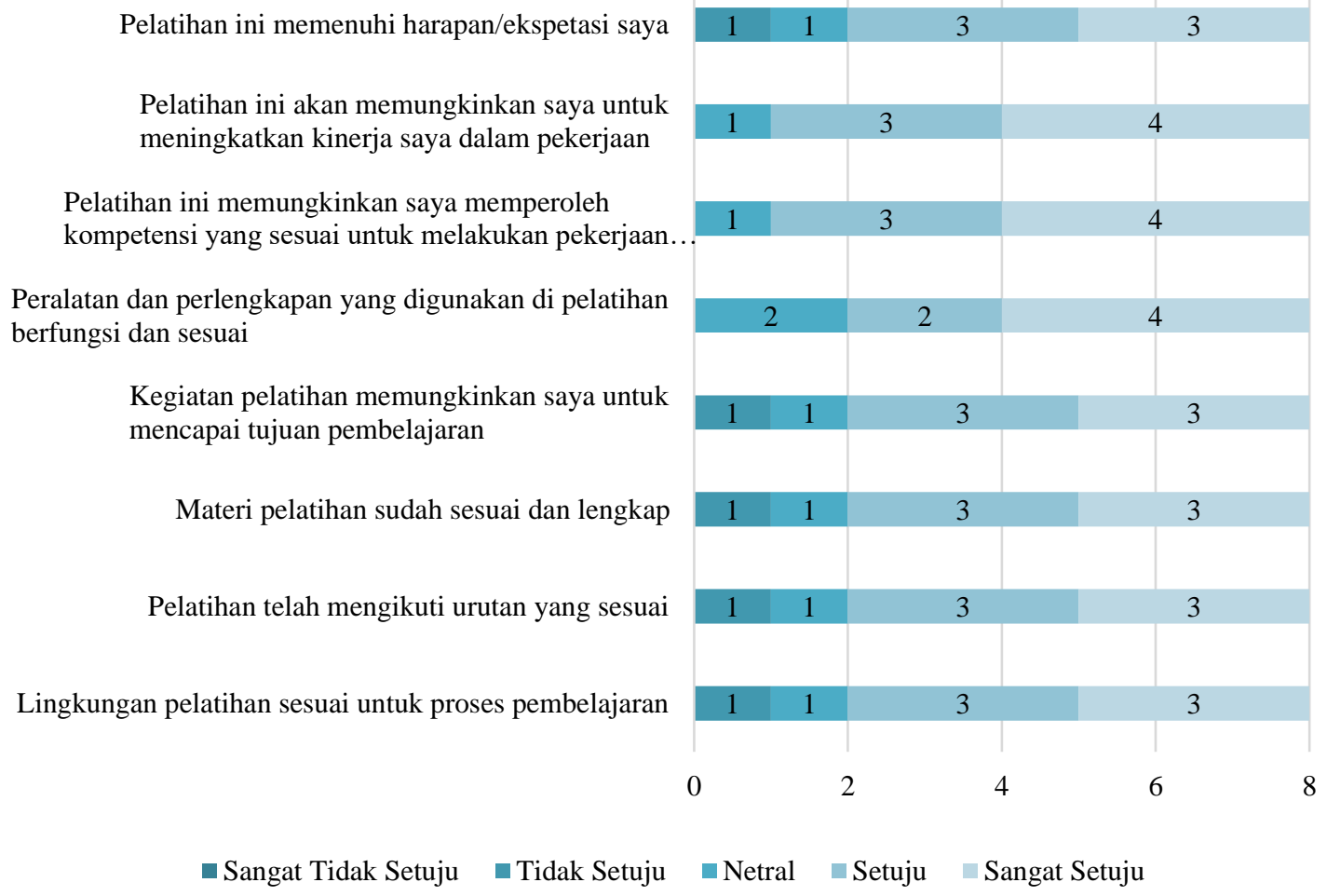

Grafik 1. Evaluasi Penyelenggaraan Pelatihan

Dari hasil evaluasi terkait isi materi (Grafik 2), dari 8 peserta yang mengisi evaluasi, 38\% menyatakan sangat setuju bahwa isi materi telah dilaksanakan secara positif, $48 \%$ menyatakan setuju, $15 \%$ menyatakan netral, dan tidak terdapat respons sangat tidak setuju dan tidak setuju.

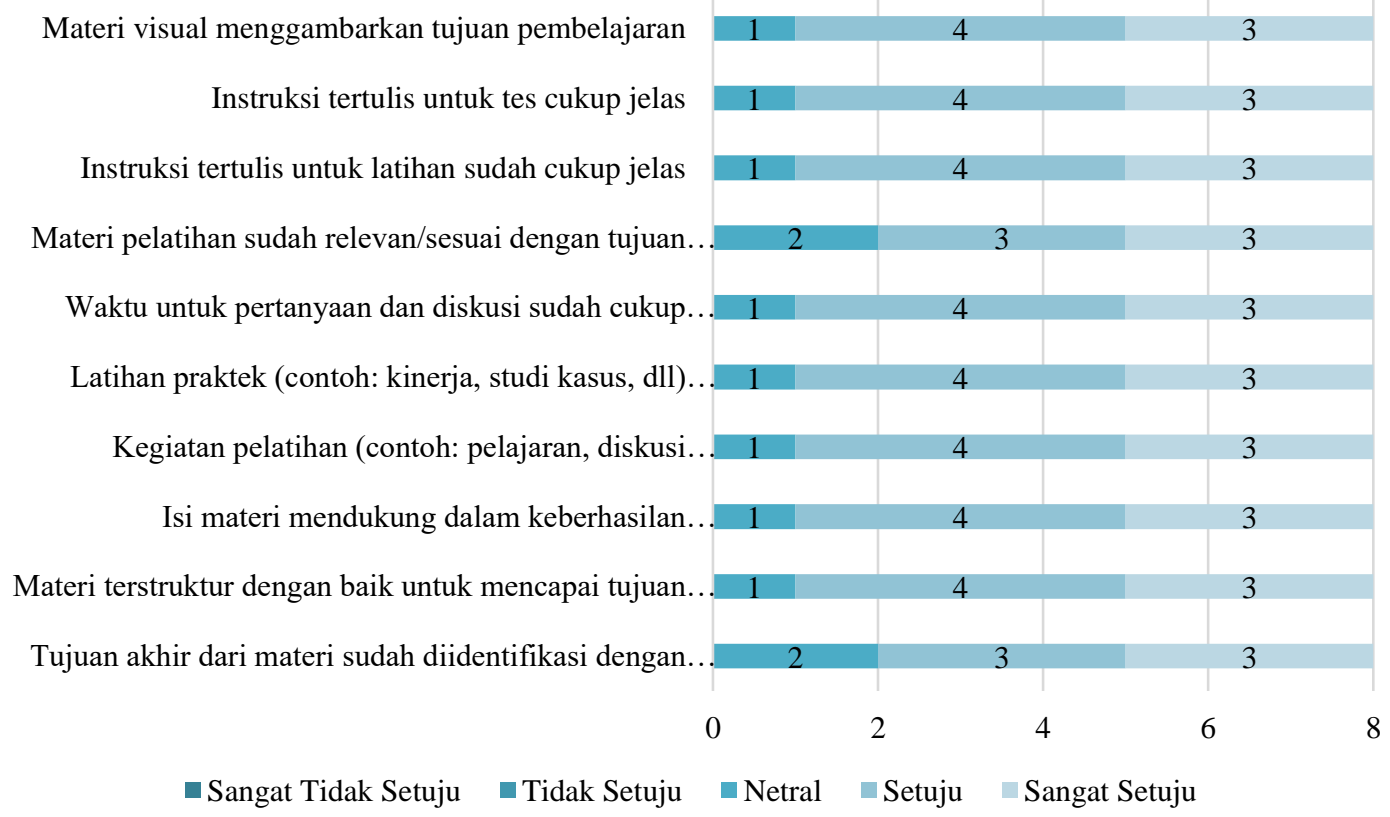

Grafik 2. Evaluasi Isi Materi Pembelajaran

Darmabakti: Jurnal Inovasi Pengabdian dalam Penerbangan

Volume 2, Nomor 1, Desember 2021 
Untuk kesimpulan penilaian aspek fasilitas kelas, dari 8 peserta terdapat respons sangat setuju sebesar $36 \%$, setuju $47 \%$, netral $14 \%$, tidak setuju $3 \%$, dan tidak ada respons sangat tidak setuju (Grafik 3).

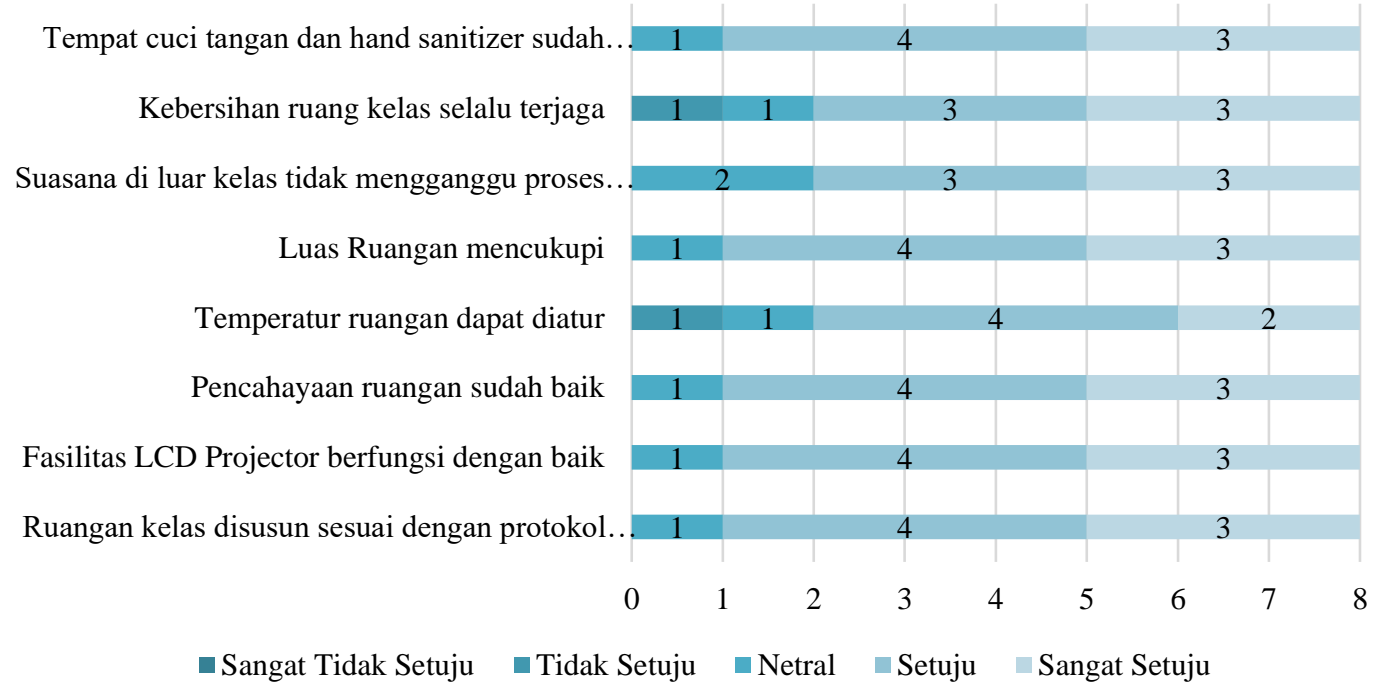

\section{Grafik 3. Evaluasi Fasilitas Kelas}

Untuk kesimpulan penilaian aspek fasilitas asrama, dari 8 peserta terdapat respons sangat setuju sebesar 34\%, setuju 33\%, netral 22\%, tidak setuju 9\%, dan sangat tidak setuju 2\% (Grafik 4).

Tempat cuci tangan dan hand sanitizer sudah tersedia

Kebersihan asrama selalu terjaga

Kamar mandi, Toilet, dan washtafel berfungsi.

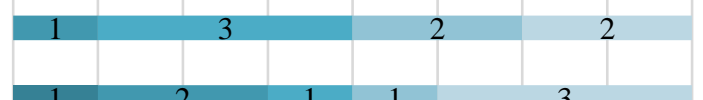

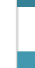

Luas ruangan kamar sudah memadai

Temperatur ruangan di kamar dapat diatur

Pencahayaan ruangan di kamar sudah bagus

Ranjang tempat tidur nyaman

Kamar telah disusun sesuai dengan protokol.
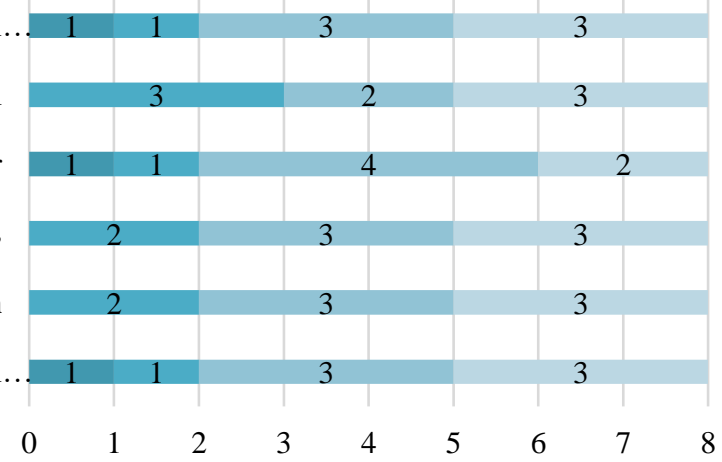

- Sangat Tidak Setuju $\quad$ Tidak Setuju $\quad$ Netral $\square$ Setuju $\square$ Sangat Setuju

\section{Grafik 4. Evaluasi Fasilitas Asrama}

Untuk kesimpulan penilaian aspek permakanan, dari 8 peserta terdapat respons sangat setuju sebesar 22\%, setuju 34\%, netral 34\%, tidak setuju 6\%, dan sangat tidak setuju 3\%. 


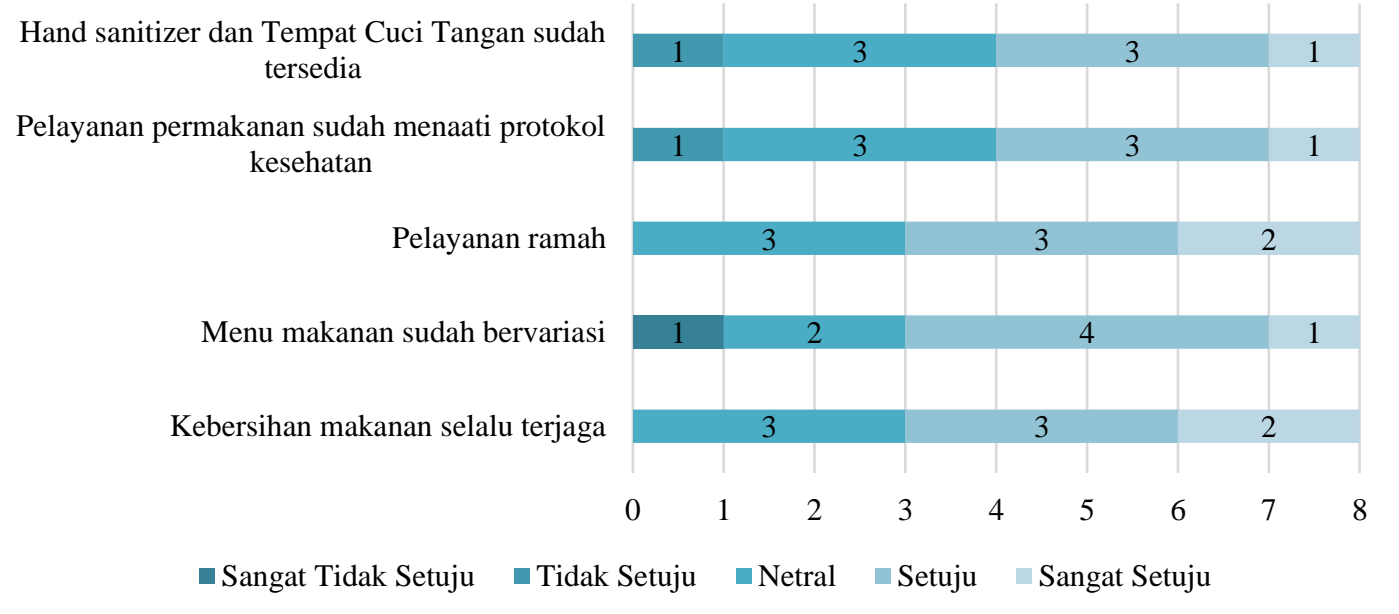

Grafik 5. Evaluasi Permakanan

Dari hasil evaluasi terkait pelayanan non-akademis, dari 8 peserta yang mengisi evaluasi, terdapat $31 \%$ respons sangat setuju dan $40 \%$ setuju terhadap pernyataan-pernyataan positif terkait aspek fasilitas kelas, fasilitas asrama dan permakanan. Selain itu, terdapat $22 \%$ respons netral, $6 \%$ respons tidak setuju, dan $1 \%$ respons sangat tidak setuju. Walaupun sebagian besar peserta telah memberikan respons yang positif, masih terdapat respons negatif terhadap pelayanan non akademis yang diberikan. Hal ini dapat menjadi fokus Politeknik Penerbangan Palembang untuk meningkatkan kualitas pelayanannya. Faktor yang dirasa kurang yaitu kebersihan asrama dan variasi menu makanan. Hasil kegiatan ini diperkuat dari hasil pelatihan (Charles, 2017; Hidayat, 2017; Puspita et al., 2021) fasilitas penunjang pelatihan yang lengkap menjadi penentu keberhasilan kegiatan yang bertujuan untuk mengembangkan keterampilan peserta pelatihan.

\section{Simpulan dan Saran}

Dapat ditarik kesimpulan bahwa kegiatan Initial Training: Teknik Pemeliharaan Kendaraan PKP-PK sebagai Sarana Pemenuhan Kompetensi Personel PKP-PK Bandar Udara dalam Kesiapsiagaan Kendaraan Operasional PKP-PK merupakan Program Pengabdian kepada Masyarakat (PkM) dosen yang melibatkan taruna Program Studi PPKP Politeknik Penerbangan Palembang. Keterlibatan para dosen, taruna dengan masyarakat bukan saja menjadi kesempatan untuk belajar dari masyarakat, namun juga memberi pengaruh positif dan aktif terhadap pengembangan masyarakat, sehingga memberi warna baru dalam pembangunan masyarakat secara positif dan saling bersinergi. Secara keseluruhan kegiatan ini berjalan dengan baik dan lancar sesuai dengan rencana yang telah disusun sebelumnya. Dengan rata-rata nilai evaluasi 80,614 (kualifikasi: baik) dapat menjadi indikator bahwa tujuan pembelajaran telah tercapai. Peserta pelatihan juga memberikan feedback yang positif terhadap pelayanan yang diberikan selama pelaksanaan pelatihan, hal tersebut dapat dilihat dari hasil evaluasi kegiatan yang secara menyeluruh berada di penilaian baik.

Saran yang dapat disampaikan berkaitan dengan hasil pelaksanaan kegiatan ini adalah: 1) sebaiknya kegiatan PkM dosen dan taruna Program Studi PPKP Politeknik Penerbangan Palembang Tahun 2021 ini dapat dilaksanakan secara periodik dan berkesinambungan. Oleh karena itu, kegiatan ini hendaknya ditindaklanjuti dengan kegiatan pengabdian berikutnya; dan 2) saran dan feedback dari peserta PkM agar dapat ditindaklanjuti dan dicari korektifnya untuk kegiatan PkM berikutnya.

\section{Ucapan Terima Kasih}

Ucapan terima kasih yang sebesar-besarnya kami tujukan kepada Lurah Sukodadi, para Ketua RT\&RW Kelurahan Sukodadi, keamanan dan Babinsa Kelurahan Sukodadi, Direktur, Kapus PPM, beserta jajarannya yang telah memfasilitasi dan memberikan kesempatan kepada tim pelaksana 
kegiatan untuk melaksanakan kegiatan pengabdian masyarakat tersebut. Mudah-mudahan kegiatan ini dapat bermanfaat bagi masyarakat sekitar Politeknik Penerbangan Palembang.

\section{Daftar Pustaka}

A Abdullah. 2020. Relationship the Work Culture and Training Programs Within Performance. International Journal of Progressive Sciences and Technologies (IJPSAT). 20 (1), pp. 92-101. https://ijpsat.ijsht-journals.org/index.php/ijpsat/article/view/1727

Abdullah, A., Nugraha, W., Masitoh, F., Sutiyo, S., \& Astutik, R. (2020). Keselamatan Diri dalam Qurban Idul Adha $1441 \mathrm{H}$ sebagai Bentuk Pengabdian kepada Masyarakat Politeknik Penerbangan Palembang. Darmabakti: Jurnal Inovasi Pengabdian Dalam Penerbangan, 1(1), 48-61. DOI: https://doi.org/10.52989/darmabakti.v1i1.12

Amalia, D., Nugraha, W., Suryan, V., Septiani, V., \& Napitulu, B. S. H. (2020). Pelatihan Basic Human Factor untuk Peningkatan Self Awareness dan Safety Culture Petugas Operasi Bandar Udara Gusti Syamsir Alam. Darmabakti: Jurnal Inovasi Pengabdian Dalam Penerbangan, 1(1), 9-18. DOI: https://doi.org/10.52989/darmabakti.v1i1.8

Arif, A., Muslim, M., Wagino, W., Nuzul, H., \& M. Yasep., S. (2020). Keterampilan Tuna Karya Bidang Perawatan dan Servis Sepeda Motor Electronic Fuel Injection. Automotive Engineering Education Journals, 1 (1), 1-12

Charles, J. (2017). Pelatihan Service Kendaraan Roda Dua bagi Kelompok Pemuda Tukang Ojek di Desa Pakuure Satu Minahasa Selatan. Jurnal LPPM Bidang Sains dan Teknologi, 4 (2), 26-32

Dudung, A., Sugeng, P., dan Ahmad, L. (2015). Pelatihan Praktik Mesin CNC bagi Guru-Guru SMK Jakarta. Sarwahita; Jurnal Pengabdian kepada Masyarakat, 12 (1), 19-25. DOI: https://doi.org/10.21009/sarwahita.121.04

Hidayat, D. (2017). Pelatihan Keterampilan Otomotif untuk Meningkatkan Kesempatan Kerja di Balai Latihan Kerja Kabupaten Karawang. Journal of Nonformal Education and Community Empowerment, 1 (1), 55-63

Lukiana. (2015). Jurnal Perhubungan Udara Pemeliharaan Kendaraan PKP-PK di Bandar Udara Hang Nadim-Batam Maintenance of Fire Fighting Vehicle in Hang Nadim Airport Batam. 41(2), 81-96

MoS CASR 139, Vol. IV. (2015). Standar Teknis dan Operasi Pelayanan Pertolongan Kecelakaan Penerbangan dan Pemadam Kebakaran (PKP-PK).

Nugraha, W., Abdullah, A., Sutiyo, S., Hendra, O., \& Marwan, I. J. (2021). Basic PKP-PK Initial Training sebagai Sarana Peningkatan Pelayanan Gawat Darurat di Bandar Udara. Darmabakti: Jurnal Inovasi Pengabdian Dalam Penerbangan, 1(2), 121-130. DOI: https://doi.org/10.52989/darmabakti.v1i2.25

Nugraha, W., Abdullah, A., Masitoh, F., Muslim, J. H., \& Sutiyo, S. (2020). Pelatihan Recurrent Basic PKP-PK bagi Pegawai Badan Usaha Bandar Udara Hang Nadim-Batam. Darmabakti: Jurnal Inovasi Pengabdian Dalam Penerbangan, 1(1), 38-47. DOI: https://doi.org/10.52989/darmabakti.v1i1.11

Nugraha, W., Amalia, D., Soleh, A. M., Masitoh, F., \& Abdullah, A. (2020). Pelatihan Safety Management System bagi Pegawai Unit Penyelenggara Bandar Udara Gusti Syamsir Alam Kotabaru. Darmabakti: Jurnal Inovasi Pengabdian Dalam Penerbangan, 1(1), 19-29. DOI: https://doi.org/10.52989/darmabakti.v1i1.9

Puspita, D., Harlin, H., \& Wadirin, W. (2021). Pelatihan Perawatan dan Service Sepeda Motor Bagi Pemuda Putus Sekolah di Ogan Ilir. Jurnal Penelitian Pendidikan, 21 (1), 1-9. DOI: https://doi.org/10.17509/jpp.v21i1.30318.

Sefrus, T., Dewanti, Sigit, P., dan Muhammad, Z. (2017). Analisis Awal Permasalahan Transportasi Udara dan Arah Pengembangan Bandara di Indonesia. Jurnal Transportasi, 17 (3), 177-184. DOI: https://doi.org/10.26593/jtrans.v17i3.2872.\%25p 
Shulfi, Z., \& Sofyan, S. (2017). Analisis Kausalitas Transportasi Udara dan Pertumbuhan Ekonomi di Indonesia. Jurnal Ilmiah Mahasiswa Ekonomi Pembangunan 